\title{
A Comparative Study To Assess The Knowledge On Nursing Care Plan Between High-Tech High-Touch Approach Users And Conventional Approach Users Among B.Sc (N) First Year Students In College Of Nursing At Chennai
}

\author{
Mrs.Kavitha.S, Prof.Mrs.S.Aruna, C.Megilin Bose Asst.prof \\ Asst.prof, Saveetha college of Nursing, SaveethaUniversity,Chennai \\ Prof.Mrs.Aruna HOD Medical Surgical Nursing Saveetha college of Nuring \\ CIMS College of Nursing, Kuntur,Andhra Pradesh.
}

\section{Introduction}

Clinical areas pose a great challenge to nursing teachers. In nursing, psychomotor skills enjoy a dominant position and professional competency of a nurse is recognized mainly by the demonstration of clinical skills. Introduction of sophisticated equipments on a regular basis to assist patient care again adds to the complex nature of clinical teaching. Considering the increased mechanization of the patient care, while teaching clinical skills teacher has to motivate the students to follow the High-tech High-touch approach in order to preserve the human component of nursing care. Through appropriate clinical teaching methods an intelligent teacher always help the student to develop an appreciable level of nursing skill

\section{Objectives Of The Study}

-To assess the knowledge on nursing care plan in two groups.

- To compare the level of knowledge on nursing care plan between two groups.

-To find out the association between their level of knowledge on nursing care plan with their selected

demographic variable.

\section{Hypothesis}

There will be significant difference in knowledge of nursing care plan between High-tech High-touch approach users and conventional approach users.

\section{Operational Definitions}

High-tech High-touch approach

It is the use of sophisticated equipment by which the student assesses the patient's condition, chooses the appropriate nursing diagnosis from menu suggested by the computer. The computer then tests possible goals and nursing interventions for those diagnosis, the student choose those appropriate for the client and types in any additional goals and interventions or nursing action not listed on the menu. The student can read the plan on the computer screen or print out an updated working copy.

\section{Research Methodology}

Descriptive approach and non-experimental design was used.The study was conducted in Saveetha College of nursing at Chennai. First year B.Sc nursing students fromSaveetha College of nursing were selected as population.Sample size is 20. Non-probability convenient sampling technique was used.The tool consists of demographic variables and observational check list consisting of 20 questions. ie (Assessmen -3, b.Diagnosis -7 c.Implementation -4 d. Evaluation - 4 e. Time -2),Data collected was analyzed using descriptive and inferential statistics.

\footnotetext{
Major findings of the study

* In High-tech High-touch approach users 19(95\%) have adequate knowledge and 1(5\%) have inadequate knowledge.

* In conventional approach users 2(10\%) have adequate knowledge, 9(45\%) moderate knowledge, $9(45 \%)$ inadequate knowledge.

* Mean and standard deviation of High-tech High-touch approach users and conventional approach users is $17.65 \& 1.42$ and $10.8 \& 3.18$ respectively.
} 
* The mean score of knowledge on nursing care plan among High-tech High-touch approach users was 17.65 higher than the mean score of conventional approach users 10.8. The ' $t$ ' value is 9.01, which is significant at $5 \%$ level of significance, $\mathrm{P}<0.05$ which revealed that there is a significant difference in knowledge of nursing care plan among students between high-tech high-touch approach users and conventional approach users.

* The chi-square value is $20 \mathrm{df}=6$ which is significant at $5 \%$ level of significance, $\mathrm{P}<0.05$ which reveals that there is a significant association between knowledge of nursing care plan and access to computer in hightech high-touch approach users.

* The chi-square value is $0.6 \mathrm{df}=6$ which is nil significant at $5 \%$ level of significant $\mathrm{P}>0.05$ which reveals that there is no significant association between knowledge of nursing care plan and access to computer in conventional approach users.

\section{Conclusion}

There is a significant difference in knowledge of nursing care plan between two groups. The study shows that majority of the students have adequate knowledge on High-tech High-touch approach of nursing care plan.

\section{Recommendations}

-A study to assess the effectiveness of High-tech High-touch Approach on knowledge of nursing care plan of B.Sc.Nursing students.

-The same study can be replicated on a larger sample to generalize the findings.

-The same study can be replicated on professional courses for higher education.

\section{References}

[1]. Acharya. (1997). Integral Education(2 ${ }^{\text {nd }}$ ed).AP: Publishing corporation

[2]. Basvanthappa. (2004).Nursing Education ( $1^{\text {st }}$ ed). New Delhi: Jaypee brothers. 120-122.

[3]. Christenson Barbara. (1999). Foundation of Nursing ( $3^{\text {rdn }}$ ed). Missouri: Mosby Publishers. 131-134

[4]. Colin, et.al., (2008). Components of Nursing process, Journal of Advanced Nursing, 12(67), 12-16 